\title{
Retour sur « Tendance et analyse des documents matériels »
}

Olivier Gosselain

\section{(2) OpenEdition \\ 12 Journals}

Édition électronique

URL : https://journals.openedition.org/tc/5061

DOI : 10.4000/tc.5061

ISSN : 1952-420X

Éditeur

Éditions de l'EHESS

\section{Édition imprimée}

Date de publication : 30 juin 2010

Pagination : 98-100

ISSN : 0248-6016

\section{Référence électronique}

Olivier Gosselain, «Retour sur « Tendance et analyse des documents matériels » », Techniques \&

Culture [En ligne], 54-55 | 2010, mis en ligne le 30 janvier 2013, consulté le 29 septembre 2022. URL : http://journals.openedition.org/tc/5061 ; DOI : https://doi.org/10.4000/tc.5061 


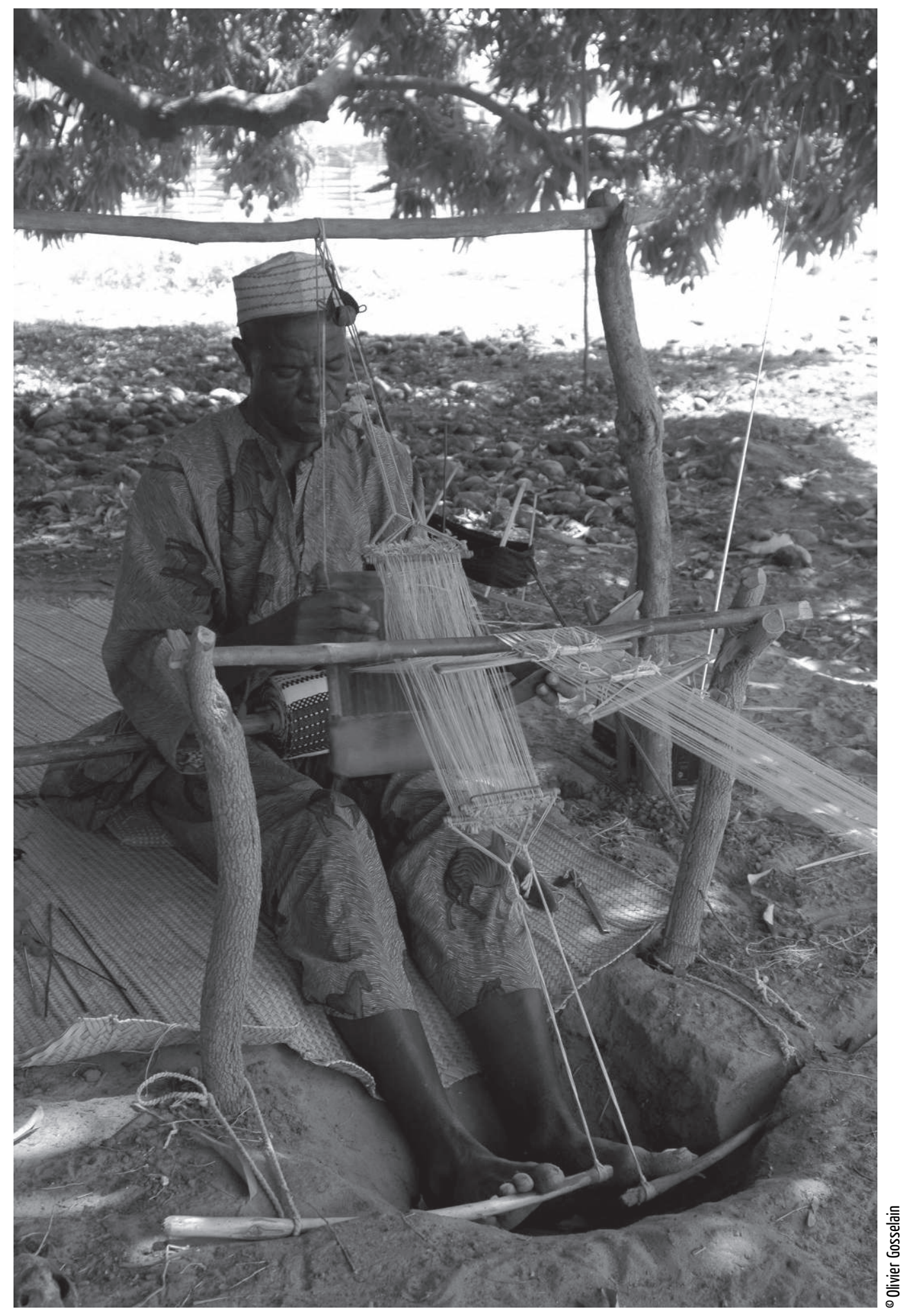




\section{Retour sur}

\section{«Tendance et analyse des documents matériels»}

Les thèmes et les lignes directrices du texte qui suit résument assez bien la carrière et la personnalité scientifique de cette figure majeure de l'ethnologie des techniques que fut Hélène Balfet. À côté de cet article, qui est l'une de ses dernières publications, le seul qu'elle ait publié dans Techniques \& Culture (si l'on excepte une remarque sur les classifications textiles, parue dans le $n^{\circ} 10$ de 1987), il faut mentionner son étude des productions de poterie en Afrique du Nord, parue en 1965 dans l'ouvrage Ceramic and Man, dont les thèmes et les questionnements se révèlent d'une remarquable modernité, sa classification des vanneries - toujours en usage - parue dans L'Anthropologie en 1952, son essai de 1981 sur la « construction de vêtements par fabrication du matériau » qui complète la typologie d'André Leroi-Gourhan (drapé, cousu droit, coupé sur le corps), ou encore les différents chapitres figurant dans son ouvrage consacré à la chaîne opératoire (1991) et traitant aussi bien de documents matériels que de cuisine ${ }^{1}$.

Le présent article est issu d'une communication présentée lors de la table ronde « Atouts et outils de l'ethnologie des techniques : sens et tendance en technologie comparée ", organisée à Paris en novembre 1992. Coorganisatrice de l'événement avec Bruno Martinelli, Hélène Balfet était alors retraitée, au terme d'une carrière essentiellement menée dans le département de Technologie comparée du Musée de l'Homme. L'objet central de la table ronde, la « tendance », n'était pas seulement un thème « leroi-gourhanien » par excellence. C'était également une notion centrale pour les technologues gravitant autour du Musée de l'Homme ou de l'Université de Provence, où H. Balfet avait brièvement enseigné au début des années 1970. Pour d'autres, et particulièrement pour certains membres de l'équipe Techniques \& Culture, la tendance était une notion problématique, soupçonnée de ramener l'analyse des faits techniques vers le fonctionnalisme. Il suffit de relire l'article de P. Lemonnier paru pratiquement à la même époque ${ }^{2}$ pour mesurer l'opposition qui 
existait entre les deux groupes de chercheurs. Cette opposition, notons-le, ne découlait pas simplement d'une filiation idéologique ou professionnelle, avec, d'un côté, les héritiers de Leroi-Gourhan travaillant à l'intersection de l'ethnologie, de la muséologie et de l'archéologie, et de l'autre, des chercheurs investissant surtout le champ de l'anthropologie culturelle et navigant entre marxisme et structuralisme. La différence portait en fait sur la conception même du document technique: objet inanimé qu'il s'agissait de nommer et de classer en partant de ses caractéristiques morphologiques pour les premiers; objet ne prenant sens qu'une fois mis en mouvement, c'est-à-dire associé à un geste technique, pour les seconds. Pour reprendre les termes éclairants de F. Sigaut, le couple structure/ fonction s'opposait ainsi au couple structure/fonctionnement ( $c f$. article précédent).

La tension entre les deux conceptions est perceptible dans les discussions reproduites au sein du volume où figure le texte. Elle l'est également dans l'article d'introduction de B. Martinelli et dans celui de R. Creswell, qui paraissent pratiquement débattre entre eux. Entre les deux, la contribution d'H. Balfet, apparaît presque comme un objet tombé du ciel. Si la position intellectuelle de l'auteure ne fait aucun doute, le texte est en effet d'une sobriété confondante - à commencer par le titre - et n'affiche aucun autre objectif que celui d'illustrer une démarche fondée sur l'analyse rigoureuse de faits techniques. L'implication dans le débat théorique se lit dès lors en creux, tout comme la formidable somme de travail effectuée en amont, qui permet à $\mathrm{H}$. Balfet d'évoquer, en dix pages, quelques problèmes centraux dans l'analyse des faits techniques. Chacun d'eux découle de la confrontation entre « logique technique et foisonnement des faits »: dans l'ordre, la question de la dénomination des objets, de la classification de « techniques complexes » - comme le métier à tisser ou la vannerie - et de ce qu'elle nomme la «critique technologique », c'est-à-dire « la prise en compte de la tendance comme outil pour apprécier la valeur des faits matériels, en vue de leur validation comme documents ethnologiques ».

Du point de vue des exemples retenus - poterie, vêtement, tissage, vannerie - elle effectue un tour d'horizon des techniques abordées au cours de sa carrière et évoque au passage quelques publications qui ont assuré sa réputation internationale. Du côté des thématiques, son article résume également les lignes de force des héritiers de LeroiGourhan: le classement des faits techniques en vue de leur exploitation comme documents historiques, la distinction entre convergence et filiation, les relations entre technique et esthétique et la nécessaire re-contextualisation des faits observés au sein de leur milieu technique. Ce dernier élément permet de souligner à quel point la notion de tendance dépasse la stricte question des contraintes techniques.

Si ce texte n'est peut-être pas le plus immédiat d'Hélène Balfet, il est par contre une excellente introduction aux façons de faire et aux façons de penser de cette personnalité majeure de la technologie. 